\author{
FRANCO MODIGLIANI \\ Massachusetts Institute of Technology \\ and
}

LUCAS PAPADEMOS

Massachusetts Institute of Technology

\title{
Targets \\ for Monetary Policy in the Coming Year
}

MOST OBSERVERS would agree that the present state of the economy can be traced largely to the monetary policy pursued during the last few quarters, in particular the severe monetary squeeze of mid-1974. We see this policy as resulting from the pursuit of inappropriate targets framed in terms of monetary aggregates and "orderly markets"- since we disbelieve that policymakers intended to achieve 9 percent unemployment, so far off any target announced by the administration or sanctioned, even indirectly, by Congress. In order to avoid similar episodes in the coming difficult quarters, monetary policy should be aimed at explicitly stated targets for real output and employment, and at consistent targets for money income. The purpose of this paper is to propose appropriate real targets for the next two years and to examine their implications for monetary policy.

In the light of the high unemployment of mid-1975, and of the importance of an orderly reduction of the current high rate of inflation, the aim proposed is to bring down the rate of unemployment over the next two years to

Note: We wish to express our appreciation to Arlie Sterling for helping us with the computations. 
a level that we label the noninflationary rate of unemployment (NIRU). It is defined as a rate such that, as long as unemployment is above it, inflation can be expected to decline-except perhaps from an initially low rate. The existence of NIRU is implied by both the "vertical" and the "nonvertical" schools of the Phillips curve. Postwar data (for the years 1953-71) are consistent with the hypothesis of a well-defined NIRU, stable over time, provided that the measure of unemployment is adjusted for changes in the composition of the labor force. Because the present labor force is heavily weighted with groups exhibiting high relative unemployment rates, NIRU as measured by the official unemployment rate is currently estimated at somewhat over $5 \frac{1}{2}$ percent. Some evidence suggests, however, that over the last two decades NIRU was held down by a favorable trend in the terms of trade between the private nonfarm sectors on the one hand and imported goods and farm products on the other. A termination or reversal of this trend would tend to raise NIRU, at least temporarily.

On the basis of these and other considerations, we conclude that a conservative interim unemployment target for mid-1977 is 6 percent. Achieving this target will require a growth of output of at least 17 percent over the next two years. Of this total, more than half should be achieved in the first year, to allow the growth rate to abate as the ultimate target is approached. Taking into account the price implications of this growth path, we conclude that in the first year money income should grow at an annual rate above 15 percent. From this it is argued that even if the primary stimulus to recovery comes from fiscal policy, as seems necessary to ensure an early and vigorous revival, the money supply will have to increase for a while at a rate well above 10 percent. There is wide concern that such a sharp acceleration in the money supply would have an unfavorable effect on the rate of inflation. But we allay this concern by showing that the evidence is clearly inconsistent with any influence of money on inflation outside of its indirect effect through its contribution to the determination of aggregate demand and employment.

We conclude that the monetary authority should be prepared to accommodate the temporary rapid rate of growth of the money supply required for the strong recovery we advocate, which we believe is consistent with a gradual abatement of inflation. By contrast, holding to monetary growth targets of the 1974 magnitude would very likely make for a sluggish recovery with rising unemployment, and might even produce a new downturn. 


\section{The Lessons of 1974}

Monetary policy in 1974 represented an unfortunate blend of two targets: (1) an endeavor to keep the growth of monetary aggregates within rigid bounds, and in particular to bring the growth of $M_{1}$ roughly within the 6 percent target foreshadowed in the 1974 report of the Council of Economic Advisers; and (2) an endeavor to prevent interest rates from falling too rapidly.

The first target was operative through July. Unfortunately, that 6 percent money growth rate was far too small to satisfy the increasing transactions requirements implied by the administration's targets for the economy for 1974: a modest growth of real income of 1 percent, an increase in unemployment between the end of 1973 and the end of 1974 from 4.9 percent to around $53 / 4$ percent, and a concomitant price increase estimated somewhat optimistically at 7 percent. Taken together, the price and output projections implied a growth of money income of about 8 percent. Warnings about the inadequacy of the 6 percent limit and the dangers of concentrating on the growth of monetary aggregates had been sounded since early in the year by many analysts, including one of the authors. ${ }^{1}$

The inconsistency became dramatically apparent as the monetary squeeze of the second quarter drove the federal funds rate from below 9 percent in early March to 13.5 percent in early July. The Federal Reserve's tolerance of such a drastic rise in short-term market rates must have reflected its aversion to significant deviations of the growth of monetary aggregates from its initial targets. The violence of the squeeze may be attributed partly also to the unreliability of the monetary statistics on which the decisions were based. Later revisions of these statistics have in fact reduced the estimated annual rate of growth of $\mathrm{M}_{1}$ in the critical four-month span from February to May from 9.7 to 7.6 percent. $^{2}$

The resulting conditions in the credit market are generally assigned the major responsibility for the decline in real gross national product in the

1. Franco Modigliani, “The 1974 Report of the President's Council of Economic Advisers: A Critique of Past and Prospective Economic Policies," American Economic Review, vol. 64 (September 1974), pp. 544-57. Although this paper was published in September, it was written in March-April, well before the squeeze.

2. We are indebted to Benjamin Friedman for bringing these figures to our attention. 
third and, especially, the fourth quarter. The Economic Report of the President, February 1975, for example, attributes to this squeeze the aborting of the mild recovery in housing in the spring and the subsequent collapse, and points out that "housing accounted for fully half of the decline in real output from 1973 to 1974. ..." (p. 41.) The credit squeeze also reduced investment, had disastrous repercussions on the stock market and hence on consumption, and directly and indirectly contributed to the desire to liquidate inventories.

After the economy began to sag, the demand for money eased and interest rates began to drop, though the decline was initially cushioned by a very slow growth of the money supply that may well have reflected the Board's desire to make up for what it perceived as the excessive growth of the first half of the year. ${ }^{3}$ In the latter part of the year, the second targetachieving a gradual fall in interest rates-became operative. To force the money supply to grow at 6 percent or thereabouts would have led to a precipitous decline in short rates, which the Board presumably regarded as undesirable. Given the sharp decline in the demand for money-due in part to falling business activity, but in part to still unsettled causes-the endeavor to bring about an "orderly" decline of interest rates meant that the money supply increased little, and even declined in early 1975 , according to the data now available.

The most important lesson of this experience is that monetary policy should not be directed to the achievement of purely monetary targets, such as rigid growth rates of monetary aggregates, or to the preservation of socalled "orderly" markets. The monetarists may be right that, given enough time and enough pain, and perhaps enough ups and downs, the economy may adjust to a $\mathrm{M}_{1}$ growth of 4 percent-provided that fiscal policy and the

3. If this interpretation has merit, the Board's actions even in July and possibly August resulted again from the unreliability of the monetary statistics; the text interpretation is suggested also by the "Record of Policy Actions of the Federal Open Market Committee" of July 16, in Federal Reserve Bulletin, vol. 60 (October 1974), especially pp. 716-17, and of August 20, ibid. (November 1974), especially pp. 766-67. The data now available indicate, in fact, that $M_{1}$ remained consistently below a 6 percent trend beginning in December 1973, except for June 1974, when it was negligibly above that trend. But in terms of the data published in the Federal Reserve Bulletin of July and August 1974, the cumulated growth of $\mathbf{M}_{1}$ was above 6 percent from March to July. A revision of these estimates apparently became available shortly before the August FOMC meeting. 
rest of the world are kind enough not to make new waves! But 1974 shows that this is not a satisfactory way to manage an economy. Instead, monetary targets should be set, and adjusted, in the light of explicitly stated goals for real output and employment and money-income targets consistent with them. Only explicit targets will make it possible to monitor the success of policymakers. In this way, too, inconsistency among the targets becomes apparent; for example, if the desired unemployment path goes along with more inflation than had been expected, a new set of targets and their policy implications should be worked out.

\section{Real Targets for the Next Two Years}

Clearly, two major problems demand urgent solution today: unemployment and inflation. Unemployment must be reduced with deliberate speed, but at the same time its planned path should lead to a steady decline in the rate of inflation. With these considerations in mind, unemployment should be gradually reduced over the next two years to an "interim" target level defined above as the noninflationary rate of unemployment, or NIRU.

The past performance of the economy permits us to identify NIRU, within bounds, and we can do so without confronting the conceptual question of the shape of the Phillips curve at extreme values. Rather, we address the more relevant question of what unemployment path is consistent with slowing inflation. For this purpose, all major views about the relation between inflation and unemployment imply the existence of a NIRU. The two extreme views carry this implication-the first that even in the long run, the Phillips curve has a negative slope throughout the entire range of unemployment; and the second that in the long run it can have no negative slope and must be vertical at some natural unemployment rate. The existence of a NIRU is also implied by intermediate positions such as our own, that the Phillips curve is relatively flat for high unemployment rates but approaches verticality (or may even be slightly backward sloping!) for sufficiently low rates of unemployment. The diagram below illustrates how the concept of a NIRU fits into these different views. The rate of inflation is measured along the vertical axis, and the rate of unemployment along the horizontal. The line $F-F^{\prime}$ is a vertical Phillips curve, à la Friedman. In this case, the NIRU is the value of $U$ at which $F-F^{\prime}$ cuts the horizontal axis, because a value of 


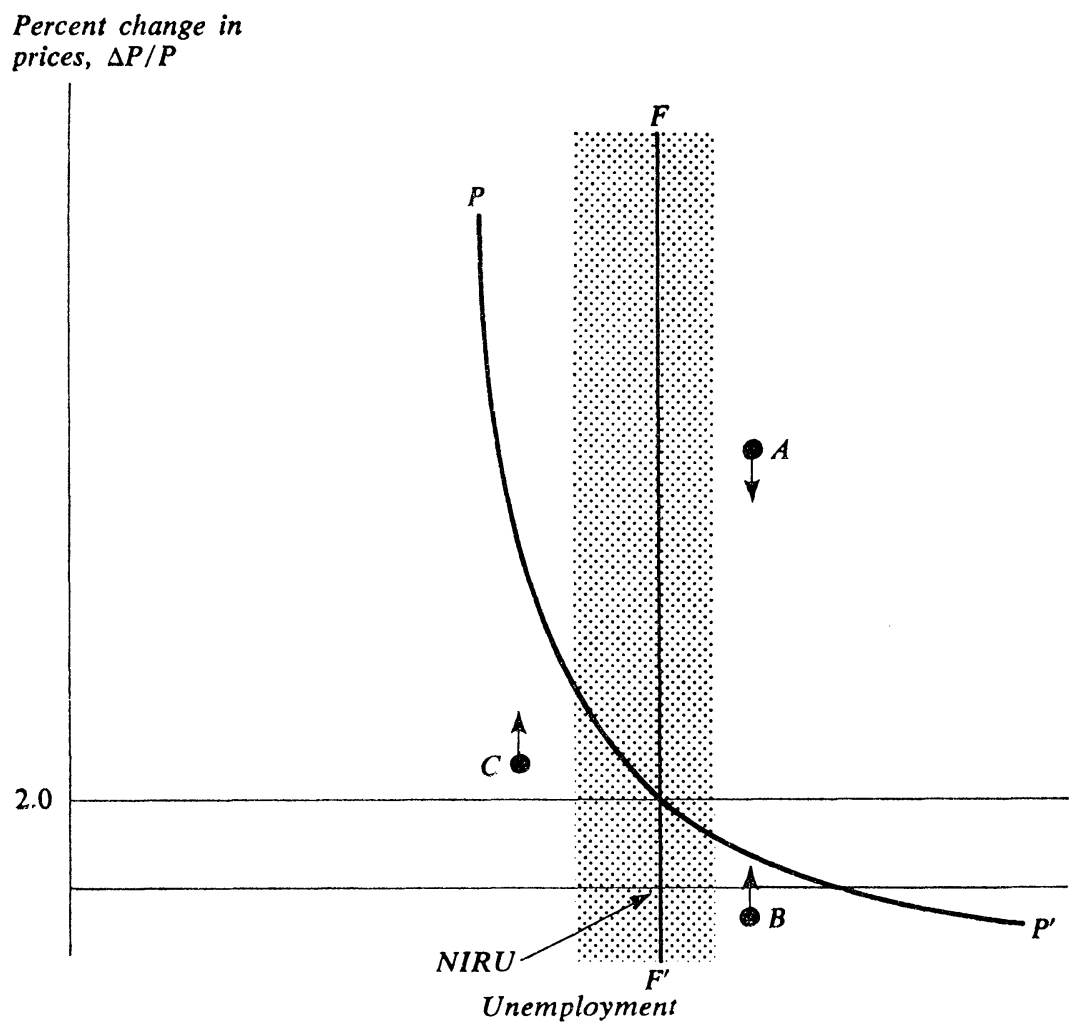

$U$ larger than NIRU must be accompanied by declining inflation, as indicated by the direction of the arrow from point $A$. Curve $P-P^{\prime}$ is a conventional Phillips curve; it may become vertical for sufficiently low unemployment and horizontal for sufficiently high unemployment, but over some middle range it has a negative slope. Here NIRU can be found by first establishing a "negligible" rate of inflation; in the diagram this rate is illustrated by 2.0 percent. The point at which the 2.0 percent inflation line intersects the $P-P^{\prime}$ curve is the NIRU corresponding to the nonvertical Phillips curve (drawn here to intersect the $F-F^{\prime}$ line so that NIRU is the same whatever the view of the inflation tradeoff). Again, whenever $U$ exceeds NIRU, but with an initial inflation rate above the negligible level, inflation must decline, as shown again by point $A$. For our purposes, the only difference between the vertical and nonvertical schools is that, for the former, the 
rate of change of prices must necessarily decline for $U$ above NIRU even if it was zero or negative to begin with, whereas for the latter it may increase if inflation was initially below the Phillips curve, at a point such as $B$.

The shading of an area on either side of NIRU indicates both uncertainty about the exact location of NIRU and the implausibility that any single unemployment rate separates accelerating and slowing inflation. Unemployment rates left of the shaded area imply a high probability that inflation will accelerate. So long as this process involves unacceptable rates of inflation, it matters little whether inflation would accelerate indefinitely (as $F-F^{\prime}$ would predict) or would approach a limit (as $P-P^{\prime}$ would predict). And as an empirical matter, unemployment rates have not been low long enough to test whether $P-P^{\prime}$ or $F-F^{\prime}$ is the better description of the tradeoff. The expectation is for accelerating inflation whenever the initial condition is little or no inflation and unemployment is to the left of the shaded area, as illustrated by point $C$.

The practical problem is determining the value of NIRU and establishing its stability over time. As to stability, the Phillips curve is known to shift with the composition of the labor force. For any given demand pressure (as measured, for example, by vacancies), various segments of the labor force tend to differ in rates of unemployment. Because significant changes in the composition of the labor force in recent years have tended to shift the tradeoff to the right and thus to increase NIRU, the stability of NIRU must be judged in light of a measure of unemployment adjusted for this composition. What follows, therefore, uses an adjusted unemployment rate, $U A$, provided by the Council of Economic Advisers, which is based on the composition of the labor force in 1956. The analysis seeks to identify a NIRUA corresponding with this employment concept.

The evidence presented in figure 1 strongly suggests that for the postwar period there exists a stable NIRUA that can be located within fairly narrow bounds. The horizontal axis measures $U A$, the adjusted unemployment rate; the vertical axis measures whether inflation went up or down in a given year, and by how much. For purposes of this figure and the subsequent regression analysis, we measure inflation by the rate of change of the consumer price index excluding food $(\overrightarrow{p c x})$. This price index is used because year-to-year changes in food prices reflect, to a considerable extent, circumstances specific to agriculture, such as weather, rather than demand pressures. The points plotted in the figure show how $U A$ and the change in the 
Figure 1. Relation between the Unemployment Rate ${ }^{a}$ and the Change in Inflation, 1953-74

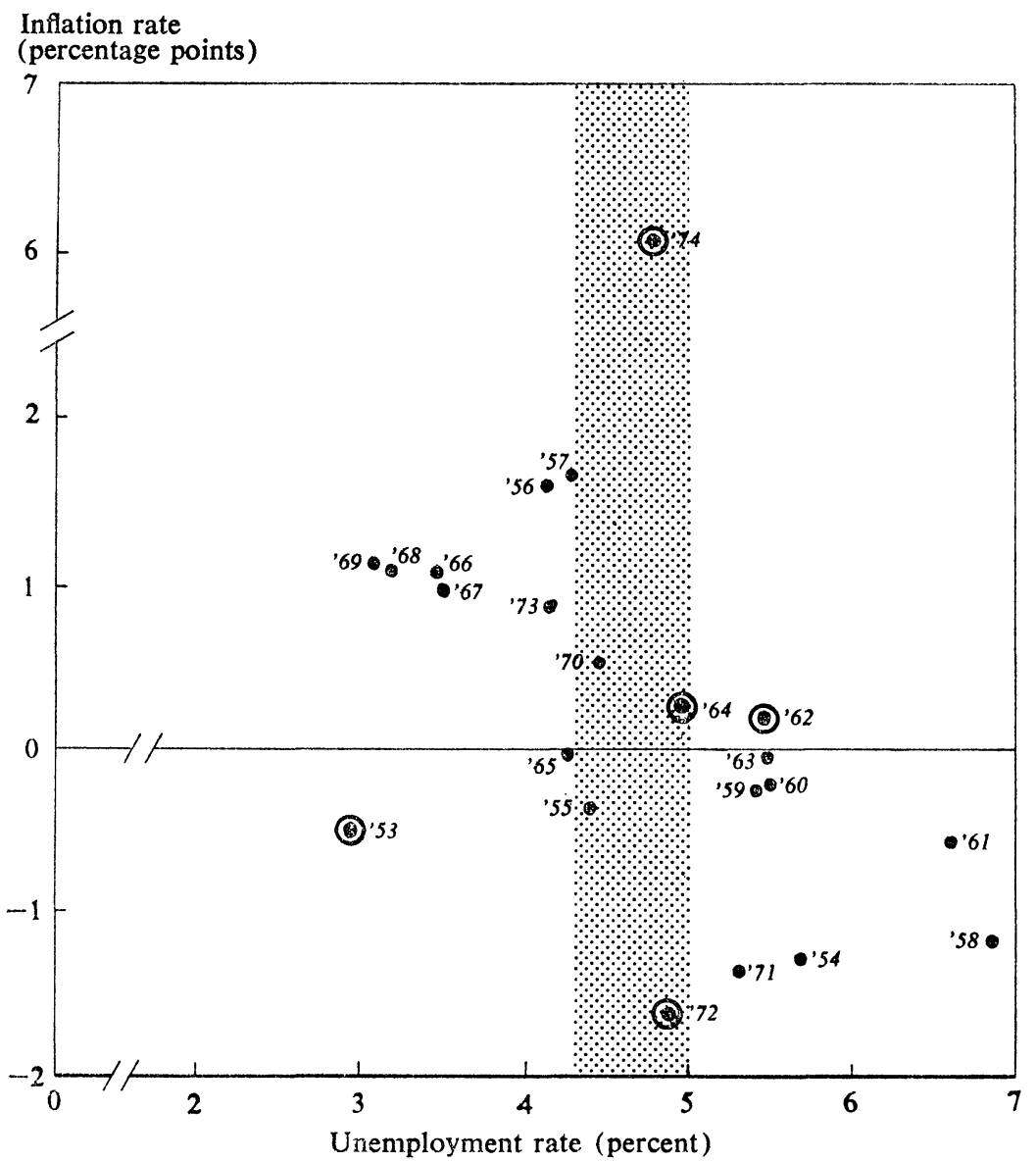

Sources: The data for the adjusted unemployment rate were provided by the Council of Economic Advisers; the change in the inflation rate is measured by the rate of change of the consumer price index excluding food, from the National Bureau of Economic Research Data Bank.

a. Adjusted, using 1956 composition of the labor force, to compensate for the changing composition of the labor force over time.

inflation rate were related each year from 1953 to 1974. Points above the solid horizontal line are years in which inflation increased and points below it are years in which inflation decreased.

The points that are circled in the figure require special comment. First, 1962 and 1964 each followed years in which inflation was at a very low rate; 


\section{ERRATUM}

The vertical axis of Figure 1 on page 148 is incorrectly labelled. It should read Change in the inflation rate. 
they correspond roughly to points like $B$ in the diagram, where inflation may speed up merely to reach a low rate of inflation predicted by current unemployment. The speedup in each of these years was less than 0.2 percentage point. Second, price and wage controls marked 1972. Third, unusual movements of raw materials prices and, in the immediately preceding years, of food prices, characterized 1953 and 1974: in 1953, these prices fell; in 1974, they rose. As the model developed below and the accompanying regression analysis will show, these price movements help account for the outlying behavior of $p c x$ in these two years.

In eight of the years plotted in figure $1, U A$ exceeds the vertical line drawn at 5 percent. In all but 1962 (circled), inflation decreased. The inference is that NIRUA is at most 5 percent. It could be somewhat lower, but the figure is ambiguous on the issue, because the next three lower observations, lying between 4.8 percent and 5.0 percent, are subject to the special factors just discussed. In nine years, $U A$ equals or falls short of the vertical line drawn at 4.3 percent. In all but two of these years, the rate of inflation increased noticeably. The exceptions are the circled year 1953, and 1965, a year again somewhat special because of the elimination or reduction of excise taxes at midyear. This evidence strongly suggests that a $U A$ of 4 percent or thereabouts represents what could be labeled the inflationary rate of unemployment, which policymakers should vigorously avoid because it leads to increasing inflation. In this region, the Phillips curve appears to be quite steep, if not vertical. On the other hand, for the two remaining years in which $U A$ fell between 4.3 percent and 4.8 percent-1955 and 1970-the response of inflation is not so consistent. The area between 4.3 and 5.0 percent $U A$ is shaded in the figure and represents the region of uncertainty about inflationary behavior.

\section{An Alternative Approach to the Estimation of NIRU}

The conclusion suggested by figure 1 can be made more precise by regression analysis. In equation (1) of table 1, estimates from a reduced-form equation are presented relating the rate of inflation in a given year to the rate of unemployment and the rate of productivity change in the same year, and to the rate of inflation in the previous year. All the variables have very significant coefficients of a priori reasonable value and the fit is fairly close, as indicated by the standard error and the $\bar{R}^{2}$. The equation was estimated 


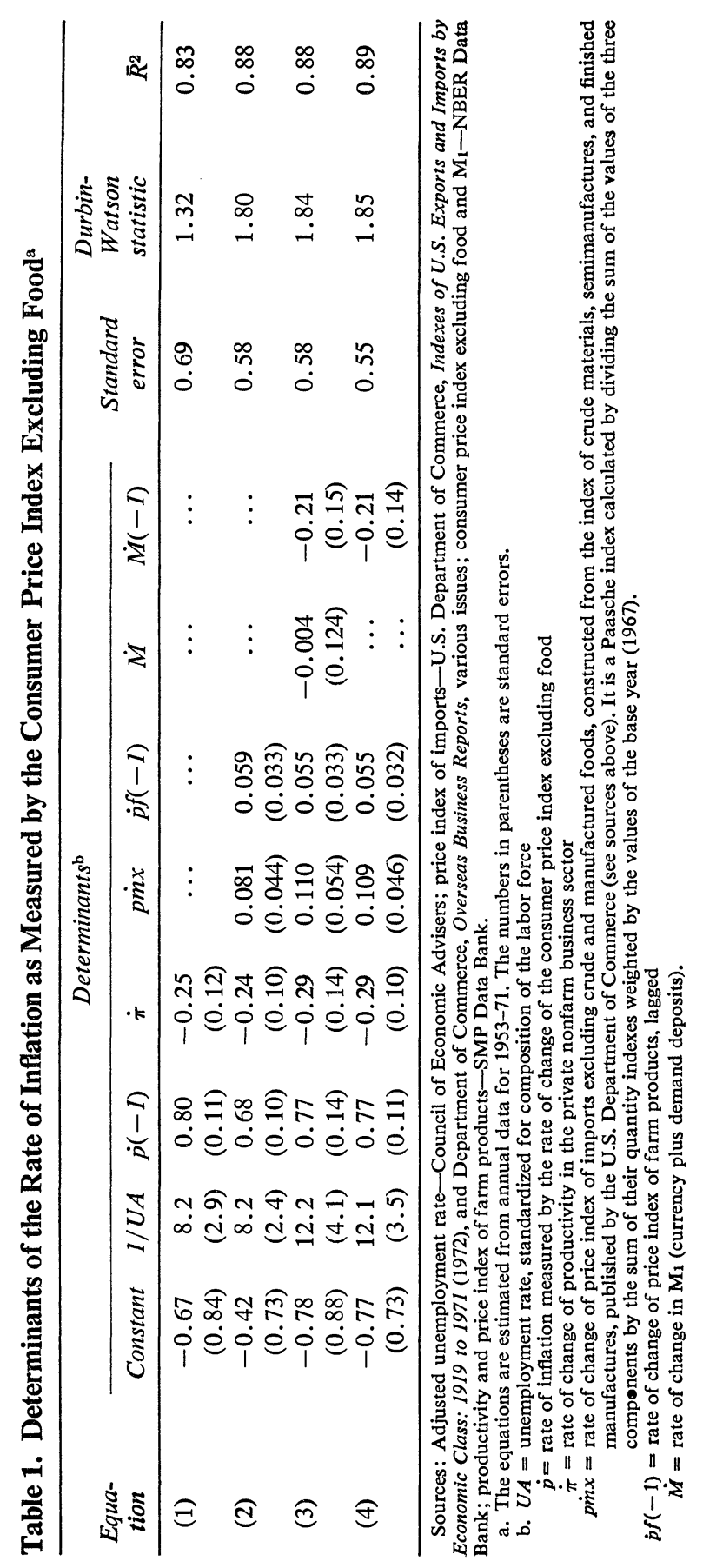


for the period 1953-71 to minimize distortions from price controls and, more recently, from increases in oil prices. The form of the equations is derived from an underlying model, presented in an appendix available from the authors on request.

Briefly, the model has three main characteristics: (1) a wage equation that accounts for the percentage change in wages in terms of the unemployment rate and expectations on the rate of change of prices; (2) a price equation that determines the long-run or target price level as a markup on unit labor cost; and (3) an allowance for the gradual adjustment of prices to their target levels and for the effect of deviations of actual productivity from its trend.

In equation (1), the dependent variable is the rate of inflation, $\vec{p}$, but this equation can be readily transformed into one accounting for the acceleration of inflation-the variable used in figure 1-by simply subtracting $\dot{p}(-1)$ from both sides. If the coefficient of $\dot{p}(-1)$ were one, the acceleration would turn out to be independent of $p(-1)$, which is the essential feature of the vertical Phillips curve. In equation (1), the estimated coefficient of $\dot{p}(-1)$ falls short of unity, though not by very much (roughly by 0.2 with a standard error of 0.1). Accordingly, estimating NIRUA requires specification of a "negligible" rate of inflation: we use 2 percent. Solving equation (1) for the unemployment rate consistent with this inflation rate yields 4.88, reported in the first row of column (8) of table 2 , which shows in the first five columns the data from table 1 for equations (1) and (2), and provides additional estimates in the other columns. This rate agrees closely with the value suggested by figure 1 . To translate NIRUA into an official unemployment rate, NIRU, 0.8 percentage point must be added to allow for the current composition of the labor force. Thus, the NIRU implied by equation (1) is around 5.7 percent (table 2 , column 10$){ }^{4}$

This estimate is rather high compared with traditional targets for unemployment, although it is not inconsistent with recent results of others. ${ }^{5}$ It might result from using $U A$ as a measure of unemployment, which is only one of many ways to account for the effect of changes in the composition of the labor force. Table 2 summarizes a number of tests designed to assess the

4. Allowing for the error term, when unemployment equals NIRU, inflation may temporarily rise or fall, even if it was initially in the neighborhood of 2 percent, but not systematically.

5. See, for example, Robert E. Hall, "The Process of Inflation in the Labor Market," BPEA (2:1974), pp. 343-93. 


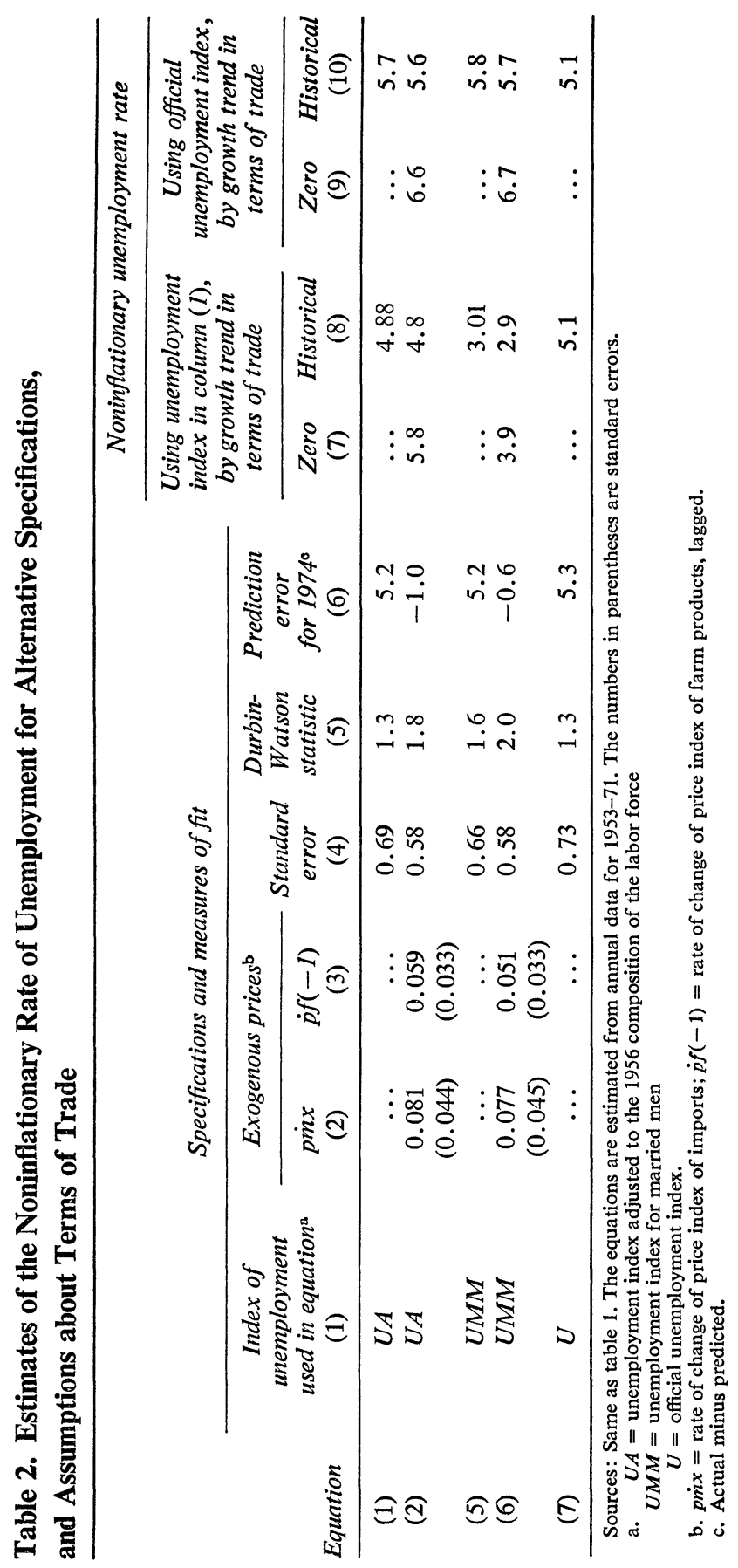


sensitivity of the estimate of NIRU to alternative specifications of the estimating equation.

Equation (5) of table 2 shows estimates obtained when $U A$ is replaced by another frequently used measure, the rate of unemployment for married men, $U M M$. Without reproducing the regression equation, which is quite similar to (1), we report in columns (4) and (5) some measures of fit; in column (8), the noninflationary rate of unemployment using the index of unemployment of married men; and in column (10) the estimate of NIRU implied by this value and the relation between $U M M$ and $U$ in the early seventies. Comparison with the statistics for equation (1) reported in table 2 shows similar fits and implied estimates of NIRU. Finally, equation (7) shows the effect of measuring labor market tightness by the official unemployment rate, $U$, itself, making no allowance for compositional effects. Here the estimate of NIRU is reduced somewhat, to 5.1. However, it is most unlikely that NIRU has remained stable over the last two decades, and the somewhat poorer fit of the equation supports this view. Hence, this estimate is not a reliable guide to the current value of NIRU.

The specification underlying equation (1) suffers from allowing only for the effect of changes in unit labor costs. The rate of change of a price index like $p c x$, the consumer price index excluding food, should depend also on the current rate of change of imported inputs, the other major component of costs (that to some extent enters into $p c x$ directly). In addition, even though $p c x$ excludes food, insofar as wage changes respond to the actual and expected behavior of prices of the basket of goods bought rather than produced by workers, ${ }^{6}$ the rate of change of $p c x(p \dot{c} x)$ should also depend, with some lag, on the rate of change of food prices. These effects might not be important for most of the period 1953-71, when the movement of these prices was relatively moderate (which may explain the reasonably good fit of equation 1), but they may be critical for years of extreme fluctuations, like 1973 and 1974 (and, incidentally, 1953). In this light, it is not surprising

6. This is not a universally acceptable hypothesis. Robert J. Gordon has emphasized the influences on wages of prices in the product markets. In his various contributions to Brookings Papers, he has stressed that prices of products produced by labor and prices of products consumed by it have independent effects on wages. Hall, in "Process of Inflation," ignores the effect of price expectations in the wage equation and questions the theoretical rationale for such a feedback (except that it may reflect the excess demand for labor). In his model, which he built around the distinction between the scale wage and the marginal effective wage, expectations on the rate of change of wages play the role of price expectations as determinants of the wage rate. 
that extrapolation of equation (1) somewhat overestimates the price change in 1972, a year of price controls, underestimates moderately in 1973, and underpredicts conspicuously the 10 percent rise of 1974 . For that year the error is over 5 percent (see table 2, column 6).

Equation (2) in table 1 reports the results of adding to the specification of (1) the current rate of change of a price index of imports excluding food, $p \dot{m} x$, and the lagged rate of change of an index of farm prices, $\not \dot{p} f(-1)$. Both variables display fairly significant coefficients and the standard error is reduced appreciably, while the serial correlation of the errors as measured by the Durbin-Watson statistic also falls substantially. The point estimates of the coefficients are not unreasonable, though they appear somewhat high. This is especially true in the case of imports, whose coefficient is larger than the share of nonfood imports in nonfood consumption or private nonfarm GNP. This result suggests that import prices affect domestic ones not only directly through their weight as inputs but also indirectly by influencing the domestic markup on labor costs (especially in the case of raw materials). In addition, the estimate of the $p \dot{m} x$ coefficient may be biased upward since, in view of U.S. dominance in world trade over the period covered, the behavior of import prices may themselves be influenced by U.S. domestic prices. Equation (6) of table 2 shows that very similar results are obtained when these additional price terms are added to the equation in which $U M M$ is used as the measure of unemployment.

The coefficient estimates are rather sensitive to the sample period and especially to the exclusion of 1953; in one sense this is understandable because 1953 was the only year up to 1971 in which these indexes behaved much differently from domestic prices. Nonetheless, this sensitivity implies that these coefficient estimates are subject to a fair margin of error. It is encouraging, however, that the equation tracks experience of recent years well. After overestimating both 1972 and 1973 somewhat, equation (2) accounts quite closely for the 10 percent rise of 1974. It does so by explicitly recognizing the importance of food prices and import prices, including those of oil, in the nation's recent experience. In 1974, it attributes some 3 percentage points of the inflation in the CPI less food to import prices and somewhat over 2 percentage points to the sharp rise of food prices in 1973. The equation actually overestimates 1974 by 1 percent (table 2, column 6), which again suggests some upward bias in the coefficient, since some underestimation might have been expected in that year.

Our main interest here is in the estimate of NIRU implied by equations 
(2) and (6), which now depends on the relation between the exogenous prices and $p \dot{c} x$. Using the historical relations inferred from the mean values of these prices over the period of fit, one obtains the estimates of NIRUA and NIRU reported in columns (8) and (10) of table 2, which agree closely with those derived earlier.

Two further, interrelated, objections to the specification of equation (2) require attention: (1) especially when dealing with annual data, one should not expect the rate of inflation to respond to unemployment without at least some lag; ${ }^{7}$ (2) our specification omits the rate of change of unemployment despite some evidence that this variable tends to have a negative effect on the rate of inflation. While each objection is valid in itself, they apparently cancel out in the annual model in which the expected lag structure interacts with the rate-of-change effect. $^{8}$

A simple model, in which the effect of unemployment on price change is approximately linear, demonstrates how this can happen. The combined effect of current and lagged $U$ and of $\Delta U$ can be expressed as

$$
\dot{p}=a U+b U(-1)+c \Delta U=(a+b) U+(c-b)[U-U(-1)],
$$

in which the constants $a, b$, and $c$ are all negative. If $b$ approximately equals $c$, neither the variable $U(-1)$ nor the variable $\Delta U$ will add significantly to the explanation of $\dot{p}$, given $U$. The reason is that for given $U$, a higher value of $U(-1)$ has two offsetting effects on $\dot{p}$ : it tends to raise $\dot{p}$ through the rateof-change effect, but it also tends to lower it through the lagged level effect. In our case, these two effects seem roughly to offset each other. ${ }^{9}$

Although the estimates of NIRU summarized in column (10) of table 2

7. Starting from a quarterly model of the form outlined earlier, one can deduce an annual model by first deriving a four-quarter change equation through recursive substitution of the lagged dependent variable, and then aggregating the four-quarter equations into an annual one. Under reasonable assumptions about the speed of adjustments, the current annual rate of change of prices in a given year depends on a distributed lag of unemployment, including the four quarters of that year and at least the six previous ones, with weights heavily concentrated in the previous year and most of the remaining weight in the current year.

8. When equation (2) is reestimated, replacing $U A$ with $U A(-1)$, the fit deteriorates somewhat. Similarly, if one adds $U A(-1)$ to $U A$, the new variable is barely significant ( $t$-ratio of 1.2). Alternatively, the fit is also somewhat worsened by using unemployment lagged two (or three) quarters - in a given year using the average unemployment rate for the four quarters ending with the second quarter of that year.

9. This explanation receives some support from a test in which $\triangle U A$ is added to the specification of equation (2); that variable is found to have the expected negative sign, but a very small coefficient $(-0.13)$ which is entirely insignificant $(t$-ratio of 0.5$)$. 
are consistent with one another and with the implications of figure $1,{ }^{10}$ they are based, explicitly or implicitly, on the relation between the index $p c x$ and the exogenous prices prevailing, on the average, over the period 1952-71. Now, in this period farm and import prices tended to increase at appreciably lower rates than the prices of the basket of goods produced off the farm, as measured by the CPI excluding food; in other words, the terms of trade moved in favor of the nonfarm population. The average rate of improvement was in fact rather substantial: 2.9 percentage points per year in terms of food and 1.7 percentage points in terms of imported nonfood commodities. If one assumes less favorable behavior of the terms of trade in the future, then any of our equations allowing for the effect of exogenous prices will imply a shift to the right in the locus of the long-run tradeoff between inflation and unemployment, and in particular a higher NIRU than in the period 1953-71. This conclusion is illustrated by columns (7) and (9) of

10. This conclusion is supported by a number of additional tests, one of which consisted in replacing $p c x$ with the private nonfarm business deflator. For this index the specification of equation (1) yields results quite similar to those of table 1 , but the implied NIRU is somewhat larger -6 percent. In specifying an equation corresponding to (2), the deflator does not directly include the price of exogenous inputs-farm products and imports-but at most a markup on these costs (which are but a small portion of total cost). It will, however, be affected indirectly to the extent that the rate of change of wages depends on the basket of goods bought; thus, in the equation below we include the change in a lagged index of farm and import prices (which were combined by simple averaging to reduce multicollinearity). In addition, we include the current rate of change of nonfood import prices on the ground, discussed in the text, that the behavior of these prices may affect the size of the domestic markup on labor costs. A test of this specification yields the following estimates (obtained using the autoregressive transformation because of a rather high negative serial correlation of the residuals):

$\dot{p}=0.005+6.9(1 / U A)+0.598 \dot{p}(-1)-0.24 \dot{\pi}$

$(0.52) \quad(1.5) \quad(0.080) \quad(0.09)$

$+0.086 p \dot{m} x+0.043[\dot{p} f(-1)+p \dot{m} x(-1)] / 2$,

with standard error $=0.49$ (adjusted to include the lagged residual) and autocorrelation equal to -0.54 .

These results are open to some question. The coefficient of current nonfood imports seems high, perhaps because of the upward bias mentioned earlier. The coefficient of lagged farm and import prices seems low and is subject to a large standard error. Nonetheless, the equation accounts surprisingly well for the 11 percent inflation rate for the deflator in 1974, underestimating it by 1 percent.

What is important for our purpose is that the NIRU implied by this equation, using historical values for the terms of trade, turns out to be 5.7, in close agreement with the estimates reported in table 2. 
table 2, which also serve to provide a notion of the sensitivity of NIRU to the terms of trade; they give the estimate of NIRU implied by each equation on the assumption of a zero growth trend in terms of trade. The effect is an increase in the estimated NIRU by about 1 percentage point.

Taken at face value, this result is rather disturbing, considering that the continuation of the favorable trend in the terms of trade after 1971 is very much in question. It is, however, subject to a number of important qualifications. First, the estimated response of NIRU to the terms of trade depends sensitively on the value of the coefficients of the exogenous prices; for reasons stated earlier, these estimates are not very reliable and are probably biased upward. Second, while, in the short run, unfavorable developments in the terms of trade seem very likely to bring higher inflation for a given unemployment rate, as our equations imply, the long-run effects are much more doubtful. A change in the trend of the terms of trade is entirely analogous in its effects to a change in the trend of productivity. In the long run, the wage Phillips curve should shift to accommodate such changes, producing a similar accommodating shift in the price Phillips curve and hence leaving NIRU roughly unchanged.

To summarize, analysis of the postwar experience points to a NIRU of just over $5 \frac{1}{2}$ percent, an estimate robust with respect to alternative specifications. In the years to come, this value will be affected by the composition of the labor force and, to some extent, by developments in the terms of trade. Considering that neither of these factors is expected to shift significantly in the near future, we propose an official rate of unemployment of around 6 percent as a reasonable, if conservative, operational target for the end of the second year following the beginning of recovery.

If, over the next two years, unemployment approaches this target from above, the rate of inflation will almost certainly decline steadily. In fact, the proposed interim target may well be too conservative; but given the present national concern with inflation, erring on that side may, in the end, provide greater assurance that a program of orderly reduction of unemployment will be adhered to.

We look forward to a significantly lower target for later years. This development might be made possible by greater sensitivity of wages to the aggregate demand for labor. But even without that, a lower unemployment target, within the nonvertical range of the Phillips curve suggested by our analysis, may be socially desirable, as James Tobin has long maintained, even though it implies a somewhat higher rate of inflation. 


\section{Implications of the Real Target for Monetary Policy}

The next question is, how much must real GNP grow over the next two years if the nation is to meet the 6 percent unemployment target? By the time income begins to recover around mid-1975, unemployment will have passed 9 percent, thus exceeding the target by 3 percentage points. Given Okun's law and the expectation of recapturing some of the recent extraordinary loss of productivity once output turns around, the recovery should start with output around 10 percent below the rate consistent with the interim unemployment target. In addition, over the two years of the plan, potential GNP should rise about another 7 percent. Thus, to meet our target, real GNP should grow by somewhat over 17 percent from the second quarter of 1975 to the second quarter of 1977, or at an average annual rate of 8 percent. However, the optimal path of recovery to the 6 percent target presumably should not be pursued at a uniform pace; rather, the rate of growth should be faster in the first year, when there is plenty of slack, and less rapid as the target is approached. Indeed, in the final quarter, the growth rate should not be much above the long-run figure of $3 \frac{1 / 2}{2}$ to 4 percent. Hence, for the first year, the real GNP growth target should be about 9 to 10 percent. While such growth is rapid by postwar standards, it is not excessive in light of the unusual slack in the economy. This conclusion is consistent with the modest effect of the change in the adjusted unemployment rate on inflation reported earlier. Furthermore, the recovery from the Great Depression was often marked by growth rates of at least that size; and they occurred even in the emergence from the 1958 contraction, without significant inflationary pressures.

Judging the implications of this real growth rate for the growth of money income calls for a realistic expectation for inflation in 1975. The administration's official target was 11 percent, but that included the effect of the oil taxes, estimated to account for 2 percentage points. The 9 percent forecast excluding the energy taxes is roughly consistent with equation (2) or the corresponding equations relying on $U M M$. If average unemployment in the first year is set at somewhat over 8 percent, if productivity growth returns to its trend value, and if import prices rise 15 percent, ${ }^{11}$ these equations would predict a decline in inflation of around a modest 1.5 percent.

11. Based on a forecast for the import deflator from Wharton Econometric Forecasting Associates, which, however, includes food prices. 
However, with an improvement of productivity growth to, say, 5 percentwhich is not implausible in the initial phase of output recovery-the decline in inflation could exceed 2 percent, reducing the year-to-year rate of change of prices below 8 percent. Variations in the rate of unemployment, on the other hand, would have minor effects; a change of 1 percentage point around a level of 8 would affect the rate of inflation by only around 0.15 point. Because of the very rapid growth of prices in 1974, however, a yearto-year growth of 8 to $8 \frac{1}{2}$ percent implies a growth of only 6 to $6 \frac{1}{2}$ percent within the year itself. Given the target real growth of 9 to 10 percent and the implied rate of price increase estimated above, the target annual rate of growth for money income over the coming year should be in the neighborhood of 16 percent.

Achieving a rate of growth of income of this magnitude obviously will require a large expansion of the money supply, though the precise figure would depend on the concomitant fiscal policy. A recovery as rapid and vigorous as that advocated would have to rely initially on massive fiscal stimuli. Monetary policy alone would not be adequate because of long lags and possible effects on the international value of the dollar that could aggravate inflation.

But even if the increase in income is achieved initially through fiscal measures, monetary policy must accommodate the increase without letting interest rates rise above current levels, at least for the first few quarters of the recovery, in particular to ensure a strong recovery of housing. Now, if income is to grow at a 16 percent rate with short-term interest rates stable, the money supply will have to rise at a rate not much lower than that. Simulations of the SMP model, as well as of some others, suggest that the achievement of this rate would require fiscal stimulants considerably stronger than those enacted so far. In their absence, the recovery would have to rely more heavily on expansionary monetary policy, and in this case, the required growth of the money supply would have to be even larger, so as to reduce interest rates below current levels.

\section{The Impact of Monetary Growth on Inflation}

At this point the analysis confronts a widely held concern, encouraged by at least some monetarists, that such a rapid rate of growth and sudden acceleration of the money supply, implying a two- to three-fold increase over 
recent rates, would unfavorably influence prices and inevitably set off a new round of inflation. Our analysis indicates that such concerns are unfounded; it implies that inflation systematically accelerates only when unemployment falls below NIRU, and the $\mathrm{M}_{1}$ growth that we expect will be needed as a component of a policy package aimed at approaching NIRU from above over the next two years.

Conceivably, one might still oppose the large growth of $M_{1}$, even in the months immediately ahead, out of fear of its causing unemployment to fall below NIRU after the first two years-that is, beyond mid-1977-and in a fashion that no action after mid-1976 could correct. Even with all due allowance for long lags, such an objection can hardly be taken seriously.

Another concern of the monetarists is that an increase in the money supply somehow has a direct effect on inflation, whatever the slack in the economy. This view is hard to credit, unless one presumes that manufacturers and merchants all over the country avidly follow the monetary statistics from the St. Louis Federal Reserve Bank and immediately raise their prices whenever the annual rate of money growth exceeds 4 percent for a month (or week). No doubt, a few people in the financial markets pore over those statistics, but mostly because they hope to infer something about the forthcoming behavior of the Federal Reserve. It is hard to believe that anybody else-except economists like us-wastes his time in this way.

But such a priori reasoning does not settle the issue; for what is incredible to us is apparently self-evident to others. The remedy is empirical evidence. On this point, the analysis already presented cannot reject the hypothesis of a direct impact of monetary growth on inflation because this possibility was not even entertained. Tests are needed to deal squarely with this issue.

In an exploration for direct correlations between money growth and inflation, the simplest relations fail. Year by year, the acceleration (or deceleration) of inflation and the acceleration (or deceleration) of money growth show no positive relation. In the post-Korean period these two variables moved more often in opposite directions than together, and the correlation between them for the 1953-71 period is about zero. Allowing for a one-year lag of prices behind money scarcely changes this result, with the correlation still only 0.08 and observations for nine out of twenty-one years going in the "wrong" direction.

Allowing for long distributed lags from money to prices sharply improves the fit of regression equations between the two. Among several tried 
with annual data for the 1953-71 period, the best was

$$
\dot{p}=-0.09+0.27 \dot{M}(-1)+0.71 \dot{p}(-1) \text {, }
$$

Standard error $=0.83 ; \quad \bar{R}^{2}=0.75$.

where $\dot{p}$ is defined as in table 1 and $\dot{M}$ is the growth rate of the money supply; the numbers in parentheses are standard errors.

Such an equation is consistent with many views of the inflation process. It implies the monetarist position that, in the long run, the rate of inflation tends to equal the rate of growth of money, up to a constant reflecting the growth trend of income and possibly of velocity (although the lag in adjustment implied by equation 8 is very long indeed). The equation is even more consistent with the view widely held by nonmonetarists that the money supply is only one of the determinants of aggregate demand, and hence of the rate of unemployment, and that monetary policy works with long lags. For instance, the SMP model, which is nonmonetarist and embodies a Phillips curve relation to explain inflation, implies a long-run relation between money and prices consistent with (8). ${ }^{12}$ However, nonmonetarists would also expect that, since in the short run $\dot{M}$ is but one of the many forces controlling aggregate demand and unemployment, the explanatory power of this variable in an equation like (8) would be rather low-which it is. ${ }^{13}$ The standard error is rather high in (8) compared with those of the equations without money in tables 1 and 2 ; also, $\dot{M}(-1)$ has a relatively low $t$-ratio, and in fact accounts for only about one-quarter of the variance of $p$ that is not accounted for by $\dot{p}(-1)$. Equation (8) also fails completely to account for the high inflation of 1974 , predicting a rate of only 4.7 percent.

The critical issue, then, is not whether in the long run money affects prices, but whether this effect results from the contribution of $M$ to the determination of unemployment or derives, at least in part, through some independent channel. This question can be readily answered by adding $\dot{M}$ to

12. Franco Modigliani, "Monetary Policy and Consumption: Linkages via Interest Rate and Wealth Effects in the FMP Model," in Consumer Spending and Monetary Policy: The Linkages, Proceedings of a Monetary Conference (Federal Reserve Bank of Boston, 1971).

13. When $\dot{M}$ replaces $\dot{M}(-1)$ in (8) yielding a somewhat different distributed lag pattern, $\dot{M}$ has a smaller and insignificant coefficient; $\vec{R}^{2}$ drops to 0.69 for the equation and lagged inflation does most of the explaining. 
equation (2) of table 1: if money has an independent effect on inflation, then the coefficient of $\dot{M}$ should remain positive and significant.

The result of this test, shown as equations (3) and (4) in table 1 , is striking and unequivocal: when $\dot{M}$ or $\dot{M}(-1)$ is added to (2), singly or in combination, the estimated coefficients turn out to be actually negative, although not very significant. The safe conclusion is that absolutely no evidence supports any systematic effect of the rate of growth of the money supply on inflation except insofar as it helps determine aggregate demand in relation to the available labor force (and possibly in relation to other determinants of productive capacity). Put somewhat differently, the evidence supports the view that the rate of inflation depends on aggregate demand through its impact on unemployment, but does not depend on the mix of fiscal policy and growth of monetary aggregates that determines the aggregate demand for labor. It follows that, in assessing the impact of monetary policy on inflation, only its influence on aggregate real demand and employment is of concern, after due consideration of concomitant fiscal actions.

For the present purpose, the essential implication of this latest test is that a rate of growth of money well above 10 percent for the next few quarters is perfectly consistent with decreasing inflation, unless one is prepared to maintain that such growth would cause unemployment to dip significantly below 6 percent within the first two years. Again, the experience of the Great Depression supports this conclusion: from 1934 to 1936, the money supply grew 37 percent with no effect on prices. ${ }^{14}$

Needless to say, a two-digit rate of growth of $M_{1}$ will not be appropriate forever, or indeed for very long. By 1976, the required growth will undoubtedly be appreciably lower. In particular, if a 9 to 10 percent growth rate is achieved beginning in mid-1975, then by mid-1976 the target growth rate of real income might be down to 7 percent, and the rate of inflation for the next year should also be down by 2 to 3 percent. Hence, the required growth in $\mathrm{M}_{1}$ might well be below 10 percent. And later on, the required rate should decline appreciably to let interest rates begin to move up appropriately. Indeed, by the time the economy nears our interim target of 6 percent unemployment, it should no longer be growing very fast, lest policy fall once again into the error, made both in 1965-66 and in 1972-73, of

14. The fact that prices did not actually fall is consistent with our analysis, given a very flat Phillips curve in the high unemployment range, and considering that, contrary to the case of 1975 , there was no inherited high inflation at the beginning of the period. 
accelerating the growth of demand just as the critical noninflationary rate of unemployment is about to be reached.

The conclusion about the high rate of growth of money that is likely to be needed to achieve the proposed targets should not be interpreted as a recommendation that the Federal Reserve adopt a rigid target of 10 or 12 percent or any other specific size. We expect the recovery to be brought about primarily by fiscal stimuli-some already in place and some yet to be enacted-and by the now somewhat easier conditions in the credit markets and their attendant interest rates. Once the recovery gets going, rapid growth of the money supply will be necessary for maintaining current market interest rates for a while, which is appropriate to sustain the recovery. Especially in light of the puzzling behavior of money demand in recent quarters, it would not be surprising if the appropriate growth rate in some future quarters were appreciably smaller or larger than the average estimate. The important point is to avoid the wild gyrations in interest rates of the last year by focusing on interest rate targets. In the initial phase of the recovery, the target should be the maintenance of current rates; after the recovery is well established, a rise in rates may become appropriate.

If the Federal Reserve should fail to accommodate the recovery in money income and insist on containing the growth of monetary aggregates within some historical average range, as in 1974, one can confidently predict that short-term market interest rates will again escalate into the two-digit range, taking the wind out of the sail of recovery and possibly causing a new recession, much as in 1974. This time, however, the episode would start from an unemployment rate of 8 percent or more, and the consequences would be far more tragic.

\section{Discussion}

THE TWO PAPERS generated lively comments about the goals of Federal Reserve policy. James Pierce observed that current monetary policy reflects the relatively heavy weighting of inflation and lower weighting of unemployment in the preferences of the policymakers. Whether monetary policy was appropriate in 1974 depends on the larger issue of whether one accepts an objective function in which inflation is weighted so heavily. In this con- 
nection, Charles Holt wondered how to reconcile the desired political independence of the Federal Reserve, which presumably empowers monetary policymakers to weight inflation and unemployment objectives, with the need for consistency in the goals pursued by fiscal and monetary policy.

Arthur Okun noted that the Federal Reserve policies of late 1974 and early 1975 could conceivably be interpreted as responses to a shift in the money-demand function. If that function did shift down, as the Pierce paper suggested, one could rationalize a policy of maintaining the interest rates that would have accompanied steady money growth in the absence of that shift; such a strategy would necessitate lowering the rate of growth of the money stock. According to Pierce's figure 2, the predicted money stock based on a demand function using actual short-term interest rates grows at a constant rate; thus it invites this interpretation. William Poole pointed out, however, that the relative sizes of shifts in the $I S$ and $L M$ curves are the relevant criteria, and that factors such as the unexpected increment to real tax revenues from inflation had shifted the $I S$ curve downward as well. More generally, policies should not offset $L M$ shifts when the $I S$ curve has shifted in the opposite direction.

Several participants cautioned against too ready acceptance of the Modigliani-Papademos target path. William Fellner was concerned about the lack of evidence supporting the choice of two years for the time path to the target. That choice has to reflect some judgment about how the inflation rate is affected by the speed at which the economy approaches the target unemployment rate, a question that is not explored in the paper. Modigliani responded that the choice of two years is supported by historical evidence (from the 1958 recession and the Great Depression) that the economy can sustain a real growth rate of around 10 percent during a recovery without adding to inflation. If anything, he regarded the 10 percent ceiling as a conservative reading of the evidence, granting that higher rates of growth might be difficult to achieve because of physical limitations.

R. J. Gordon offered a "disciplinarian's" viewpoint on the inflationary implications of an easy money policy that might work through the international side. Under a system of flexible exchange rates, easy money would cause a dollar devaluation and thus bring about higher inflation in several ways. With the devaluation acting as an incentive for expanded exports of primary products, capacity limitations in those industries would be reached at a higher rate of unemployment than otherwise. Also, the change in relative world prices would lead to shifts in world and domestic demand. By 
treating price indexes for foreign and raw materials as exogenous variables, Modigliani and Papademos may have underestimated the inflationary impacts of expansive monetary policies. Michael Wachter highlighted another aspect of international complications, noting that economic expansion would be accelerated by a sharp increase in demand by OPEC members for U.S. goods. To accommodate such a possibility without risking an acceleration in inflation, monetary and fiscal policy may have to proceed more cautiously.

The empirical results in the Modigliani-Papademos paper drew some discussion. Lawrence Klein stated that his recent econometric work had uncovered a small, but significant, direct effect of the money supply on price changes. James Tobin doubted that the rise in what is considered a noninflationary rate of unemployment is due entirely to demographic shifts in the labor force. Alternatively, he argued, the level of employment at which the economy encounters rapid inflation reflects both raw material supplies and the size of the capital stock. Extended periods of weak economic activity hold down investment and capacity growth and thus result in the appearance of bottlenecks and inflation at higher rates of unemployment than previously. If the nation tolerates a slow recovery with high unemployment and hence low investment, the estimates of the noninflationary unemployment rate will be even higher several years from now.

Tobin also raised the issue of the proper mix of monetary and fiscal policy. He felt that even though, as Modigliani and Papademos claimed, tight money may have been primarily responsible for the downturn, fiscal stimulus would be necessary in the recovery because the Federal Reserve may be unwilling to do enough to revive the economy or may be unable to reverse fully and promptly with low interest rates the depressive effects of previously high rates. Robert Solomon believed that the role of tight money in the recession was being overemphasized. Other factors pulled down the economy as well, most notably a full employment surplus averaging more than $\$ 20$ billion in the first three quarters of 1974 and a quadrupling of oil prices that drained away another $\$ 20$ billion. 